\title{
Evaluasi Pelaksanaan Praktikum Biologi di SMA Negeri di Klaten pada ditinjau dari Kualitas Laboratorium, Pengelolaan, dan Pelaksanaan Praktikum
}

\section{Evaluation of the Implementation of Biology Practicum in Public High School in Klaten in terms of Laboratory Quality, Practicum Management and Implementation}

\author{
PUTRI AGUSTINA $^{1 *}$, ALANINDRA SAPUTRA ${ }^{2}$, EVA KHUSNUL KHOTIMAH $^{1}$, DWI \\ ROHMAHSARI ${ }^{1}$, NUNUK SULISTYANTI ${ }^{1}$ \\ ${ }^{1}$ Program Studi Pendidikan Biologi FKIP Universitas Muhammadiyah Surakarta, Jl. A. Yani Tromol Pos 1 Pabelan Kartasura, \\ Sukoharjo, Indonesia \\ ${ }^{2}$ Program Studi Pendidikan Biologi FKIP Universitas, Jl. Ir. Sutami No. 36 A Kentingan Jebres, Surakarta, Indonesia \\ *Corresponding authors: pa182@ums.ac.id
}

Manuscript received Revision accepted:

\begin{abstract}
Practicum is one of the learning methods that cannot be separated from Biology learning. Practicum becomes a vehicle for training and developing science process skills and scientific attitudes of students. Practicum can run well if it is carried out in accordance with the standards of practicum implementation. This study aimed to evaluate the implementation of Biology practicum in one of Pubic High School in Klaten covering laboratory quality, management, and the implementation of 2017/2018 Biology semester practicum. This research is a descriptive research. The parameters studied included the quality of the laboratory, management of the lab, and the implementation of the Biology lab. Data collection techniques are carried out by observation, documentation, and interviews. The results showed that: (1) the quality of the Biology laboratory was in the good category with a percentage of $66.5 \%$; (2) Biology practicum management is included in the good category with a percentage of $63.75 \%$; and (3) Biology practicum is included in the excellent category with a percentage of $95.23 \%$.
\end{abstract}

Keywords: Biology practicum, laboratory quality, practicum management, practicum implementation

\section{PENDAHULUAN}

Permendikbud Nomor 22 Tahun 2016 tentang Standar Proses Pendidikan Dasar dan Menengah menyebutkan bahwa pembelajaran pada Kurikulum 2013 menekankan pada pendekatan ilmiah (scientific approach), tematik terpadu, dan tematik yang dapat diterapkan melalui pembelajaran berbasis discovery atau inquiry learning, problem based learning, dan atau project based learning. Pembelajaran sesuai dengan tuntutan tersebut menekankan pada empat pilar pendidikan menurut UNESCO yaitu learning to know, learning to do, learning to be, dan learning to live together (Laksana, 2016).

Biologi merupakan salah satu cabang dari sains (IPA) yang mempelajari tentang makhluk hidup dan kehidupannya. Mastika, Adnyana, \& Setiawan ( 2014) menyatakan bahwa Biologi berkaitan dengan cara mencari tahu tentang alam secara sistematis, sehingga tidak hanya berupa kumpulan pengetahuan yang berupa fakta, konsep, atau prinsip tetapi juga merupakan suatu proses penemuan. Berdasarkan tuntutan tersebut, maka pembelajaran Biologi harus menekankan pada pengalaman langsung untuk mengembangkan kompetensi agar siswa mampu menjelajahi alam sekitar secara ilmiah. Salah satu wujud pengalaman langsung yang diberikan kepada siswa adalah melalui penerapan metode praktikum.

Praktikum merupakan salah satu metode pembelajaran yang dilakukan untuk menemukan atau membuktikan suatu konsep atau prinsip yang telah ada atau yang dirumuskan para ahli. Apabila ditinjau dari segi siswa, maka kegiatan praktikum ini adalah kegiatan untuk menemukan konsep atau prinsip, dan bila ditinjau dari segi ahli, maka kegiatan ini adalah proses verifikasi konsep atau prinsip. Praktikum merupakan salah satu metode pembelajaran yang dapat menumbuh kembangkan sikap rasa ingin tahu siswa, aktif, kreatif, inovatif, dan kejujuran ilmiah dalam menghadapi suatu masalah dalam realita kehidupan (Muna, 2016).

Praktikum merupakan kegiatan yang menjadi ciri khas dalam pembelajaran Biologi. Banyaknya konsep Biologi yang kompleks menuntut untuk diselenggarakannya kegiatan pembelajaran yang memudahkan siswa untuk mempelajari konsep tersebut. Kegiatan praktikum sangat sesuai untuk 
memfasilitasi siswa belajar melalui pengalaman langsung. Praktikum memberikan kesempatan kepada siswa untuk mendapatkan gambaran dalam keadaan yang nyata tentang apa yang diperoleh dalam teori dan terjadi kontak inderawi. Selain itu, dalam kegiatan praktikum siswa tidak sekedar mengamati secara langsung tetapi harus menghayati, terlibat langsung dalam perbuatan dan bertanggungjawab terhadap hasilnya (Chodijah, 2016).

Praktikum dapat berjalan dengan baik apabila didukung dengan sarana dan prasarana penunjang yang memadai. Laboratorium merupakan sarana utama yang mendukung terselenggaranya praktikum. Laboratorium menurut Mastika et al. (2014) adalah tempat dilaksanakannya kegiatan percobaan dan penelitian. Pada pembelajaran IPA/Biologi siswa tidak hanya mendengarkan pembelajaran yang diberikan guru mata pelajaran tertentu, tetapi ia harus melakukan kegiatan sendiri untuk mendapatkan dan memperoleh imformasi lebih lanjut tentang ilmu pengetahuan di laboratorium.

Standar laboratorium Biologi yang baik tertuang dalam Permendiknas Nomor 24 tahun 2007 tentang standar sarana dan prasarana untuk Sekolah Dasar/Madrasah Ibtidaiyah (SD/MI), Sekolah Menengah Pertama/Madrasah Tsanawiyah (SMP/MTs), dan Sekolah Menengah Atas/Madrasah Aliyah (SMA/MA). Adapun sarana dan prasarana ruang laboratorium yang memenuhi Permendiknas Nomor 24 tahun 2007 adalah: (1) kapasitas mampu memuat satu rombongan belajar; (2) luas lahan laboratorium 2,4m2/peserta didik; (3) memiliki fasilitas atau cahaya yang memadai; (4) memiliki perabot; (5) memiliki peralatan pendidikan berupa alat peraga dan alat \& bahan percobaan; (6) media pendidikan; (7) bahan habis pakai; dan (8) perlengkapan lain.

Selain kelengkapan sarana dan prasarana, kualitas dan keberhasilan praktikum ditentukan oleh pengelolaan praktikum. Pengelolaan praktikum meliputi pengelolaan laboratorium, pemanfaatan laboratorium, perencanaan serta administrasi praktikum. Pengelolaan didalam praktikum sangat penting, pengelolaan prakikum yang tidak dikelola dengan baik dapat menyebabkan jalannya pembelajaran di dalam laboratorium menjadi terhambat. Pengorganisasian dan pengelolaan dilakukan melalui sosialisasi tentang hak dan kewajiaban pengelola dalam melaksanakan tugas dan tanggung jawabnya.

Dengan didukung kualitas laboratorium dan pengelolaan praktikum yang baik, diharapkan pelaksanaan praktikum dapat berjalan dengan lancar. SMA Negeri 1 Polanharjo adalah salah satu sekolah yang telah terakreditasi A, walaupun berada di pedesaan. SMA Negeri 1 Polanharjo juga telah menerapkan proses pembelajaran K13 (Kurikulum 2013), K13 diterapkan pada kelas X dan XI sedangkan kelas XII masih menggunakan Kurikulum Tingkat Satuan Pendidikan (KTSP). Berdasarkan wawancara awal sekolah telah memiliki laboratorium dan juga fasilitas laboratorium yang dapat menunjang kegiatan praktikum, tetapi kegiatan praktikum di SMA Negeri 1 Polanharjo baru berjalan efektif selama dua tahun.

Penelitian ini bertujuan untuk mengevaluasi pelaksanaan praktikum Biologi di SMA Negeri 1 Polanharjo Klaten meliputi kualitas laboratorium, pengelolaan, dan pelaksanaan praktikum Biologi semester genap 2017/2018.

\section{METODE PENELITIAN}

Penelitian ini merupakan penelitian deskriptif yang bertujuan menggambarkan kualitas laboratorium, pengelolaan, dan pelaksanaan praktikum Biologi di SMA Negeri 1 Polanharjo Klaten. Penelitian dilaksanakan di SMA Negeri 1 Polanharjo Klaten pada bulan Februari sampai Juli 2018. Data, sumber data, dan teknik pengumpulan data pada penelitian ini disajikan pada Tabel 1 .

Tabel 1. Data, Sumber Data, dan Teknik Pengumpulan Data

\begin{tabular}{cccc}
\hline Data & Aspek & Sumber Data & Teknik Pengumpulan Data \\
\hline Kualitas Laboratorium & Ruang Laboratorium & Laboratorium Biologi & Observasi \\
& Sarana Perabot Laboratorium & & \\
& Peralatan Pendidikan & & \\
& Media Pendidikan & & \\
& Bahan Habis Pakai & & \\
& Perlengkapan Lain & & \\
& Pengelolaan Laboratorium & Laboran, wakasek & Observasi, dokumentasi, \\
& kurikulum, guru & wawara \\
& Pemanfaatan Laboratorium & Biologi, kepala & \\
& Perencanaan Praktikum & laboratorium & \\
& Administrasi Praktikum & Siswa, guru, PBM & Observasi, dokumentasi, \\
& Persiapan, Pelaksanaan, dan & wawancara \\
\hline \multirow{2}{*}{ Pelaksanaan Praktikum } & Evaluasi Praktikum & & \\
& & &
\end{tabular}


Analisis data dilaksanakan secara deskriptif kualitatif menggunakan rumus:

$$
\text { Nilai }=\frac{\text { Skor perolehan }}{\text { Skor maksimal }} \times 100 \%
$$

\section{HASIL PENELITIAN DAN PEMBAHASAN}

\section{Kualitas Laboratorium}

Laboratorium merupakan tempat penelitian agar siswa menguasai konsep atau teori tertentu dengan cara praktik atau mengalami langsung (Musfah, 2017). Fungsi utama dari laboratorium adalah sebagai sarana untuk siswa agar dapat mempraktikkan apa yang telah dipelajari di dalam kelas sehingga teori-teori yang diberikan di dalam pembelajaran kelas dapat diaplikasikan langsung ke katagori:

Kemudian nilai tersebut diinterpresikan berdasarkan

$\begin{array}{ll}81-100 \% & \text { : Sangat Baik } \\ 61-80 \% & \text { : Baik } \\ 41-60 \% & \text { : Cukup Baik } \\ 21-40 \% & \text { : Kurang Baik } \\ 0-20 \% & \text { : Sangat Kurang Baik }\end{array}$

sasaran (Indrawan, 2015). Dalam ruang laboratorium harus tersedia perabot dengan lengkap sebab dengan adanya perabot serta pemasangan yang tepat akan menunjang kelancaran kegiatan belajar mengajar, secara praktik. Kelancaran kegiatan laboratorium akan sangat tergantung dari kecepatan dan ketepatan penyediaan/penyiapan alat dan bahan serta kondisi fisik dari alat dan bahan yang diperlukan (Arikunto \& Yuliana, 2008).

Hasil observasi laboratorium Biologi di SMA Negeri 1 Polanharjo Klaten tahun pelajaran 2017/2018 disajikan pada Tabel 2 .

Tabel 2. Hasil Observasi Kualitas Laboratorium Biologi di SMA Negeri 1 Polanharjo Klaten Tahun Pelajaran 2017/2018

\begin{tabular}{ccc}
\hline Aspek & Nilai $(\%)$ & Kategori \\
\hline Ruang Laboratorium & 100 & Sangat Baik \\
Sarana Perabot Laboratorium & 57 & Cukup Baik \\
Peralatan Pendidikan & 36 & Kurang Baik \\
Media Pendidikan & 100 & Sangat Baik \\
Bahan Habis Pakai & 46 & Cukup Baik \\
Perlengkapan Lain & 60 & Cukup Baik \\
\hline Rata-Rata & 66.5 & Baik \\
\hline
\end{tabular}

Berdasarkan Tabel 2 diketahui bahwa kualitas laboratorium Biologi di SMA N 1 Polanharjo Klaten termasuk kategori baik dengan presentase nilai $66,5 \%$. Hal ini karena terdapat sarana perabot laboratorium, peralatan pendidikan, bahan habis pakai dan perlengkapan lain yang belum memenuhi jumlah standar sarana dan prasarana laboratorium Biologi yang telah ditetapkan Permendiknas Nomor 24 Tahun 2007 tentang standar sarana dan prasarana untuk Sekolah Dasar/Madrasah Ibtidaiyah (SD/MI), Sekolah Menengah Pertama/Madrasah Tsanawiyah (SMP/MTs), dan Sekolah Menengah Atas/Madrasah Aliyah (SMA/MA).

Aspek yang sudah sesuai dengan standar yaitu ruang laboratorium dan media pendidikan. Hal ini ditunjukkan dengan dalam satu ruangan laboratorium Biologi mampu menampung 2-3 rombongan belajar atau sekitar 29 siswa, luas lahan laboratorium Biologi berukuran 122,4 $\mathrm{m}^{2}$ yang dapat digunakan untuk 29 siswa. Didalam ruang laboratorium Biologi terdapat ruang penyimpanan dan ruang persiapan yang memiliki luas $24 \mathrm{~m}^{2}$ namun kedua ruangan tersebut memiliki luas yang berbeda. Adapun luas ruang penyimpanan adalah $9 \mathrm{~m}^{2}$ dan ruang persiapan adalah $15 \mathrm{~m}^{2}$. Rasio luas lahan ruang laboratorium untuk masing-masing peserta didik yaitu $3.39 \mathrm{~m}^{2}$. Fasilitas atau pencahayaan yang ada di laboratorium Biologi telah memadai yang didukung dengan adanya lampu neon dan ventilasi atau jendela sehingga dapat digunakan oleh peserta didik untuk membaca buku dan mengamati obyek percobaan. Selain itu, media Pendidikan yang digunakan adalah papan tulis berwarna putih yang berada didepan bagian tengah sehingga peserta didik dapat melihat papan tulis dengan jelas.

Aspek yang belum sesuai atau kurang dari standar diantaranya adalah sarana perabot laboratorium, peralatan pendidikan, bahan habis pakai, serta perlengkapan lain.

Pada aspek sarana perabot laboratorium, terdapat lemari penyimpanan alat dan bahan tidak dapat dikunci dan hanya ditutup, serta bak cuci yang tersedia terdapat lima buah namun yang berfungsi dengan baik hanya dua buah karena saluran air pada tiga bak cuci mengalami kerusakan.Peralatan pendidikan yang belum memenuhi standar Permendiknas adalah preparat meiosis, preparat anatomi tumbuhan dikotil dan monokotil, preparat anatomi hewan, gambar kromosom, gambar tumbuhan dan hewan dari berbagai divisi, gambar sistem pencernaan cacing, gambar sistem pernapasan hewan, gambar sistem reproduksi hewan, gambar sistem syaraf hewan, mikroskop stereo, perangkat pemeliharaan mikroskop, gelas arloji, cawan petri, gelas beaker, corong, pipet ukur, tabung reaksi, sikat tabung reaksi, penjepit tabung reaksi, 
erlenmeyer, kotak preparat, lumping dan alu, gelas ukur, stop watch, kaki tiga, perangka batang statif, klem universal, boss head, pembakar spiritus, kasa berbahan baja, aquarium, sumbat karet 1 dan 2 lubang, termometer, fotometer, termometer suhu tanah, serta manual percobaan.

Bahan habis pakai yang kurang dari standar yaitu asetokarmin serbuk hanya terdapat 5 gram, eosin padat (kristal) hanya terdapat 18 gram, glukosa padat hanya terdapat 430 gram, $\mathrm{KOH}$ padat (kristal) hanya terdapat 250 gram, MnSO4 hanya terdapat 250 gram, $\mathrm{NaOH}$ hanya terdapat 270 gram, dan vaseline hanya terdapat 270 gram. Sedangkan menurut Permendiknas Nomor 24 Tahun 2007 masing-masing bahan memiliki ukuran $500 \mathrm{ml} / \mathrm{lab}, 500$ cc/lab, dan $2500 \mathrm{ml} / \mathrm{lab}$.

Berdasarkan uraian di atas maka diketahui bahwa kualitas laboratorium Biologi di SMA Negeri 1 Polanharjo Klaten masuk dalam kategori baik meskipun masih ada beberapa aspek yang belum atau kurang dari standar yang ditentukan. Kualitas laboratorium yang baik diharapkan dapat berkontribusi pada meningkatnya kualitas proses pembelajaran sehingga hasil belajar menjadi lebih baik. Masih belum sesuainya kualitas laboratorium dengan standar yang ditentukan menjadi masalah utama di satuan pendidikan yang lain. Mastika et al., (2014) pada hasil penelitiannya menunjukkan bahwa fasilitas daya dukung sarana prasarana yang ada di ruang laboratorium IPA/Biologi yang ada di 8 SMA Negeri Kota Denpasar belum memenuhi standar yaitu dengan persentase $80.56 \%$.

\section{Kualitas Pengelolaan Praktikum}

Hasil observasi pengelolaan praktikum Biologi di SMA Negeri 1 Polanharjo Klaten tahun pelajaran 2017/2018 disajikan pada Tabel 3 .

Tabel 3. Hasil Observasi Kualitas Pengelolaan Praktikum Biologi di SMA Negeri 1 Polanharjo Klaten Tahun Pelajaran 2017/2018

\begin{tabular}{ccc}
\hline Aspek & Nilai $(\%)$ & Kategori \\
\hline Pengelolaan Laboratorium & 68.75 & Baik \\
Pemanfaatan Laboratorium & 68.75 & Baik \\
Perencanaan Praktikum & 81.25 & Sangat Baik \\
Administrasi Praktikum & 100 & Sangat Baik \\
\hline Rata-Rata & 63.75 & Baik \\
\hline
\end{tabular}

Berdasarkan Tabel 3, diketahui bahwa kualitas pengelolaan praktikum di SMA Negeri 1 Polanharjo Tahun Pelajaran 2017/2018 secara keseluruhan masuk dalam kategori baik dengan perolehan nilai sebesar $63,75 \%$, hal ini dikarenakan masih terdapat beberapa aspek pengelolaan praktikum di SMA Negeri 1 Polanharjo yang masih terkendala. Pada aspek pengelolaan laboratorium, kualitas sarana dan prasarana yang baik kurang diimbangi dengan penataan yang sesuai fungsinya. Salah satu contohnya misal rak alat dan bahan diruangan laboratorium SMA Negeri 1 Polanharjo berada di dalam lemari yang sudah terpisah antara alat dan bahan tapi penataannya kurang rapi dan kurang terawat. Alat- alat peraga di dalam laboratorium sudah tertata dengan rapi dan diletakkan strategis yaitu didalam lemari dan juga di atas lemari sehingga terlihat oleh siswa dan dapat menunjang kegiatan belajar peserta didik, tetapi diruangan laboratorium belum dilengkapi dengan petunjuk keselamatan kerja sehingga masih berbahaya ketika siswa melakukan kegiatan praktikum karena siswa tidak memakai jas laboratorium, glove maupun masker yang dapat menghindarkan siswa dari bahan-bahan yang berbahaya ketika kegiatan praktikum berlangsung.

Laboratorium SMA Negeri 1 Polanharjo juga telah memiliki preparat awetan tetapi preparat awetan tersebut penataannya tidak dipisah antara preparat awetan hewan, manusia dan tumbuhan sehingga pada saat kegiatan praktikum menggunakan preparat tersebut siswa harus mencari dan dapat menyita waktu. Herbarium kering yang dimiliki laboratorium tidak dalam kondisi terawat karena dibiarkan terletak di sela-sela antar lemari. Herbarium kering yang seharusnya dapat dimanfaatkan untuk menunjang kegiatan siswa tetapi tidak dimanfaatkan dan di biarkan dalam kondisi sangat kotor, bahkan herbarium basah yang dimiliki laboratorium juga tidak terawat. Herbarium basah ini dalam keadaan tercampur antar hewan satu dengan yang lainnya.

Ruangan laboratorium telah dilengkapi dengan poster gambar yang diletakkan secara strategis yang diletakkan diatas jendela dan dalam keadaan terawat sehingga dapat menunjang kegiatan belajar siswa. Ketika di dalam ruangan laboratorium terjadi hal-hal yang tidak diinginkan seperti, kebakaran laboratorium telah menyiapkan 1 buah APAR yang diletakkan di ruang persiapan dalam keadaan masih dibungkus plastik sehingga apabila terjadi kebakaran membutuhkan waktu untuk membuka plastik tersebut. APAR seharusnya dalam kondisi siap untuk digunakan. Ruang laboratorium tidak dilengkapi dengan denah yang dapat mempermudah siswa untuk mengetahui tata letak alat dan bahan yang akan di gunakan siswa dalam kegiatan praktikum.

Ruangan laboratorium memiliki wastafel 6 buah tetapi air tidak dapat mengalir hal ini dikarenakan terdapat pipa yang bocor. Aliran listrik pun belum sesuai standar, menurut Permendiknas No.24 Tahun 2007 aliran listrik terdapat 9 buah tetapi di ruang laboratorium SMA Negeri 1 Polanharjo hanya terdapat 8 buah tetapi 1 aliran listrik dalam keadaan rusak belum diperbaiki hal ini bila dibiarkan terus menerus dapat menghambat kegiatan praktikum.

Pengelola laboratorium (kepala laboratorium, guru pengampu praktikum, dan laboran) merupakan sosok yang penting dalam pelaksanaan praktikum sehingga pengelola laboratorium diharapkan benar-benar mengetahui keadaan laboratorium. Pengelolaan laboratorium merupakan salah 
satu faktor keberhasilan kegiatan praktikum (Rustaman, 2005).

Pemanfaatan laboratorium di SMA Negeri 1 Polanharjo masuk kategori baik dengan presentase $68,75 \%$, terdapat beberapa hal yang belum terpenuhi diantaranya adalah daftar pembagian tugas dilaboratorium sehingga guru yang memakai laboratorium pada hari tersebut harus menyiapkan dan juga membersihkan sendiri setelah praktikum selesai. Untuk penyusunan daftar pemakaian laboratorium di SMA Negeri 1 Polanharjo sesuai dengan jadwal pelajaran biologi dengan tata letak peralatan yang efektif tetapi ada beberapa barang yang rusak yang belum dipisahkan. Jenis alat dan bahan beserta jumlahnya di dalam laboratorium sudah sesuai dengan yang di praktikumkan, siap untuk digunakan praktikan dengan jumlah yang sesuai dengan jumlah praktikan dan layak untuk digunakan, sehingga setiap kelompok mendapatkan alat bahan yang akan dipraktikumkan.

Efektifitas pemanfaatan laboratorium merupakan pengukuran sejauh mana laboratorium dapat dimanfaatkan oleh pihak sekolah melalui pemanfaatan fungsi-fungsi laboratorium dalam kegiata praktikum secara efektif. Pemanfaatan laboratorium secara efektif dapat mencapai tujuan pembelajaran, pemanfaatan laboratorium dalam menunjang pembelajaran guna mencapai kompetensi secara optimal (Hasibuan \& Moedjiono, 2006).

Aspek perencanaan praktikum dan administrasi praktikum di SMA Negeri 1 Polanharjo sudah dikategorikan sangat baik. Presentase yang di dapatkan pada aspek perencanaan praktikum yaitu $81,25 \%$, presentase ini belum mencapai $100 \%$ dikarenakan siswa berdiskusi dengan suara lantang sehingga mengganggu kelompok lain, sehingga ruangan tidak kondusif. Pelaksanaan kegiatan praktikum juga tidak sesuai dengan program semester yang telah dibuat, seharusnya materi sistem ekskresi pada manusia di program semester diajarkan bulan februari minggu ke 4 tetapi diajarkan pada bulan maret minggu ke 4, untuk materi yang di praktikumkan sudah sesuai dengan materi yang dicantumkan di dalam program semester dan Praktikum yang dilakuan sudah sesuai dengan buku panduan praktikum dan produk berhasil yang selanjutnya siswa ditugaskan untuk membuat laporan yang telah dipraktikumkan.

Perencanaan praktikum merupakan rancangan pelaksanaan pembelajaran yang akan direalisasikan didalam lingkungan belajar dan merupakan penjabaran lebih rinci dari silabus. Perencanaan pembelajaran yang baik meliputi silabus/rencana pembelajaran semester dan satuan acara pembelajaran (SAP) yang memuat identitas mata pelajaran, pencapaian pembelajaran, kemampuan akhir yang diharapkan, materi (topik), pengalaman belajar, sumber belajar, alokasi waktu dan penilaian (Sofyan, 2016).

Aspek administrasi praktikum di SMA Negeri 1 Polanharjo presentasenya mencapai $100 \%$ karena di SMA Negeri 1 Polanharjo memiliki dokumen-dokumen dropping dari pusat untuk menunjang kegiatan praktikum. SMA Negeri 1 Polanharjo juga memiliki inventaris alat dan bahan yang ada di laboratorium yang digunakan untuk memantau alat yang rusak dan sudah tidak layak digunakan serta bahan-bahan di dalam laboratoruim yang sudah habis. Lemari yang ada di dalam laboratorium SMA Negeri 1 Polanharjo semua sudah di labeli dengan keterangan alat atau bahan apa saja yang ada di lemari tersebut, dengan begitu siswa maupun guru tidak kesulitan untuk mencari alat atau bahan yang akan dipakai.

\section{Kualitas Pelaksaaan Praktikum}

Data kualitas pelaksanaan praktikum diperoleh berdasarkan observasi pada aspek persiapan, pelaksanaan, dan evaluasi praktikum. Observasi dilakukan pada tiga praktikum yaitu Sistem Pencernaan, Sistem Pernafasan, dan Sistem Ekskresi. Hasil observasi kualitas pelaksanaan praktikum di SMA Negeri 1 Polanharjo Klaten pada semester genap tahun pelajaran 2017/2018 disajikan pada Tabel 4.

Tabel 4. Hasil Observasi Kualitas Pelaksanaan Praktikum Biologi di SMA Negeri 1 Polanharjo Klaten Tahun Pelajaran 2017/2018

\begin{tabular}{ccc}
\hline Aspek & Nilai $(\%)$ & Kategori \\
\hline Persiapan & 97.5 & Sangat Baik \\
Pelaksanaan & 100 & Sangat Baik \\
Penutup (Evaluasi dan Tindak Lanjut) & 89.28 & Sangat Baik \\
\hline Rata-Rata & 95.23 & Sangat Baik \\
\hline
\end{tabular}

Berdasarkan Tabel 4, diketahui bahwa kualitas pelaksanaan praktikum di SMA Negeri 1 Polanharjo Klaten semester genap tahun ajaran 2017/2018 sangat baik dengan rata-rata total sebesar $96,42 \%$. Pada aspek persiapan praktikum, beberapa hal yang diamati antara lain: (1) guru mempersiapkan tempat pelaksanaan praktikum; (2) guru mempersiapkan peralatan yang digunakan untuk praktikum; (3) guru mempersiapkan bahan yang digunakan untuk praktikum; (4) guru menjelaskan penggunaan alat praktikum; (5) guru memberikan instruksi penggunaan bahan praktikum; (6) guru memberikan kesempatan kepada siswa untuk bertanya mengenai instruksi yang telah disampaikan; (7) guru menjelaskan tujuan praktikum kepada siswa; (8) guru menjelaskan tujuan praktikum kepada siswa; (9) guru memberikan motivasi kepada siswa; (10) guru memberikan LKS praktikum kepada siswa; serta (11) guru memberi kesempatan siswa untuk mengerjakan LKS.

Pembelajaran Biologi di SMA Negeri 1 Polanharjo Klaten sebagian besar sudah diajarkan melalui kegiatan praktikum. Siswa di sekolah ini sangat menyukai praktikum. Praktikum dapat membantu siswa dalam 
mengingat materi. Sehingga diharapkan siswa dapat mengerjakan soal-soal yang diberikan guru. Hal ini sesuai dengan penelitian (Dewi, Sunariyati, \& Neneng, 2016) yang menyatakan bahwa siswa cenderung menyukai pembelajaran Biologi pada saat mereka merasa dapat memahami pelajaran yang disampaikan dan pada saat Biologi diajarkan dengan serangkaian kegiatan tertentu misalnya praktikum. Siswa bersemangat saat mengikuti kegiatan praktikum karena ketika kegiatan praktikum berlangsung mobilitas mereka dalam belajar cukup tinggi.

Adanya praktikum diharapkan siswa di SMA Negeri 1 Polanharjo Klaten dapat memiliki motivasi yang tinggi. Menurut penelitian Hamidah, Sari, \& Budianingsih, (2013)bangkitnya motivasi siswa dalam belajar biologi dengan adanya laboratorium dapat meningkatkan hasil belajar siswa tersebut. Hal ini sesuai dengan penelitian (Hartini, 2014) yang menyatakan bahwa motivasi dapat menumbuhkan keinginan siswa untuk lebih giat dan rajin dalam belajar sehingga akan mendapatkan hasil belajar yang memuaskan, karena motivasi adalah modal dasar dalam proses belajar. Selain itu, menurut penelitian (Ulfa, 2016), praktikum juga dapat membangkitkan motivasi belajar IPA, khususnya Biologi. Motivasi dapat mempengaruhi seberapa dalam siswa untuk belajar. Praktikum memberi kesempatan kepada siswa untuk memenuhi dorongan rasa ingin tahu dan ingin bisa. Prinsip ini sangat menunjang kegiatan praktikum yang di dalamnya siswa menemukan pengetahuan melalui eksplorasinya terhadap alam. Siswa bersemangat ketika mengikuti kegiatan praktikum karena ketika kegiatan praktikum berlangsung mobilitas mereka dalam belajar cukup tinggi, sedangkan ketika membuat laporan hasil praktikum tidak semua siswa cenderung benar-benar dapat bekerja sama dengan baik bersama teman sekelompoknya (Dewi et al., 2016).

\section{KESIMPULAN}

Berdasarkan hasil penelitian dan analisis data maka dapat ditarik kesimpulan: (1) kualitas laboratorium Biologi masuk dalam kategori baik dengan persentase $66.5 \%$; (2) pengelolaan praktikum Biologi masuk dalam kategori baik dengan persentase $63.75 \%$; serta (3) pelaksanaan praktikum Biologi masuk dalam kategori sangat baik dengan persentase $95.23 \%$.

\section{DAFTAR PUSTAKA}

Arikunto, S., \& Yuliana, L. (2008). Manajemen Pendidikan. Yogyakarta: Aditya Media.

Chodijah, S. (2016). Analisis Pelaksanaan Praktikum pada Pembelajaran Biologi Siswa Kelas VIII di SMP Negeri 1 Seputih Raman Kabupaten Lampung Tengah Tahun Pelajaran 2015/2016. Universitas Lampung.

Dewi, I. S., Sunariyati, S., \& Neneng, L. (2016). Analisis Kendala Pelaksanaan Praktikum Biologi di SMA Negeri se-Kota Palangka Raya. EduSains, 2(1), 1326.
Hamidah, A., Sari, N., \& Budianingsih, R. S. (2013). Manajemen Laboratorium Biologi Beberapa SMA Swasta di Kota Jambi. Jurnal Sainmatika, 7(1), 1-10.

Hartini, S. (2014). Analisis Proses Pembelajaran Biologi Pada Materi Sistem Reproduksi Manusia di Kelas XI SMA Negeri 3 Lengayang Kabupaten Pesisir selatan. Universitas Negeri Padang.

Hasibuan, J., \& Moedjiono. (2006). Proses Belajar Mengajar. Bandung: Remaja Rosdakarya.

Indrawan, I. (2015). Pengantar Manajemen Sarana dan Prasarana Sekolah. Yogyakarta: Deepublish.

Laksana, S. D. (2016). Integrasi Empat Pilar Pendidikan (UNESCO) dan Tiga Pilar Pendidikan Islam. AlIdarah: Jurnal Kependidikan Islam, 6(1), 43-61.

Mastika, I. N., Adnyana, I. B. P., \& Setiawan, I. G. N. A. (2014). Analisis Standarisasi Laboratorium Biologi dalam Proses Pembelajaran di SMA Negeri Kota Denpasar. E-Journal Program Pascasarjana Universitas Pendidikan Ganesha, 4, 1-10.

Muna, I. A. (2016). Optimalisasi Fungsi Laboratorium IPA Melalui Kegiatan Praktikum pada Prodi PGMI Jurusan Tarbiyah STAIN Ponorogo. Kodifikasia, 10(1), 109-131.

Musfah, J. (2017). Manajemen Pendidikan Teori, Kebijakan, dan Praktik. Jakarta: Kencana.

Rustaman, N. (2005). Strategi Belajar Mengajar Biologi. Malang: UM Press.

Sofyan, H. (2016). Penyusunan Panduan Praktikum Applied Approach Buku 2. Yogyakarta: UNY Press.

Ulfa, S. W. (2016). Pembelajaran Berbasis Praktikum: Upaya Mengembangkan Sikap Ilmiah Siswa pada Pembelajaran Biologi. Nizhamiyah, VI(1), 65-75. 